\title{
Copyright Protection and Cultural Industry-Theoretical and Empirical Studies
}

\author{
Jie-Jing $Y A O^{1, a}$, Hui PENG ${ }^{2, b,{ }^{*}}$ \\ ${ }^{1}$ Shanghai University of Political Science and Law, China \\ ${ }^{2}$ Shanghai Academy of Social Sciences, China \\ ayaojiejing@163.com, bpenghui@sass.org.cn \\ ${ }^{*}$ Corresponding author
}

Keywords: Cultural Industry, Copyright Protection, Theoretical Studies, Empirical Studies.

\begin{abstract}
The nature of copyright law is to establish an optimal equilibrium relationship between creators and users. Too strong or too weak a copyright protection is not necessarily beneficial to the balance of interests among copyright holders, imitators, and the public. This paper reveals the inherent mechanism of copyright protection in the cultural industry from both theoretical and empirical perspectives and explains the basic methods and principles in copyright protection in the four stages -creating, developing, promoting and consuming -- of innovation in the value chain of the cultural industry.
\end{abstract}

\section{Raising the Question}

According to one of the important missions in the National Intellectual Property Strategy, which stated "the aim to promote the development of the cultural industry", copyright protection should "promote the ability of cultural innovation" and "facilitate the sustainable development of industries relating to copyright." Exploring effective incentives to accelerate the process of upgrading the cultural industry so as to drive socio-economic cultural development has become a focus in academia. One of the paths for reference relies on knitting copyright protection and the development of the cultural industry closely together.

Currently, academia has conducted fairly in-depth studies on the principle of the importance of copyright protection[1][2][3][4][5], and has reached consensus on copyright institutions being conducive to promoting and encouraging the supply of innovative works and being beneficial to the renewal, promotion and development process of current works for copyright owners or creators. Based on this knowledge, Berne Convention, Universal Copyright Convention, Rome Convention and a series of other international treaties have established the importance of the concept of copyright protection. Major countries have also established and perfected the legislation of copyright protection. In China, our government has committed to strengthening copyright protection since the 1990s, and has so far completed two legislative amendments. The third amendment has also been under way since July 2011.

At the same time, however, copyright is a monopoly in nature. In the pursuit of profit maximization, it is highly possible for copyright owners to expand their monopoly right at the expense of public interest. This hinders public access to the work and impedes the growth of the knowledge for the whole society. Scholars have also generally acknowledged and accurately analyzed the principle of limited copyright protection[6][7].But how do we take both the importance of and the limitation on copyright protection into consideration and perform a detailed analysis? How do we discuss the method and the path of copyright protection based on the development of the cultural industry? And how to propose a basic principle of copyright protection in response to the different value activities of the different stages of the cultural industry? Here academic views diverge, and this paper will further the discussion based on current studies. 
Introduction to Theoretical Background

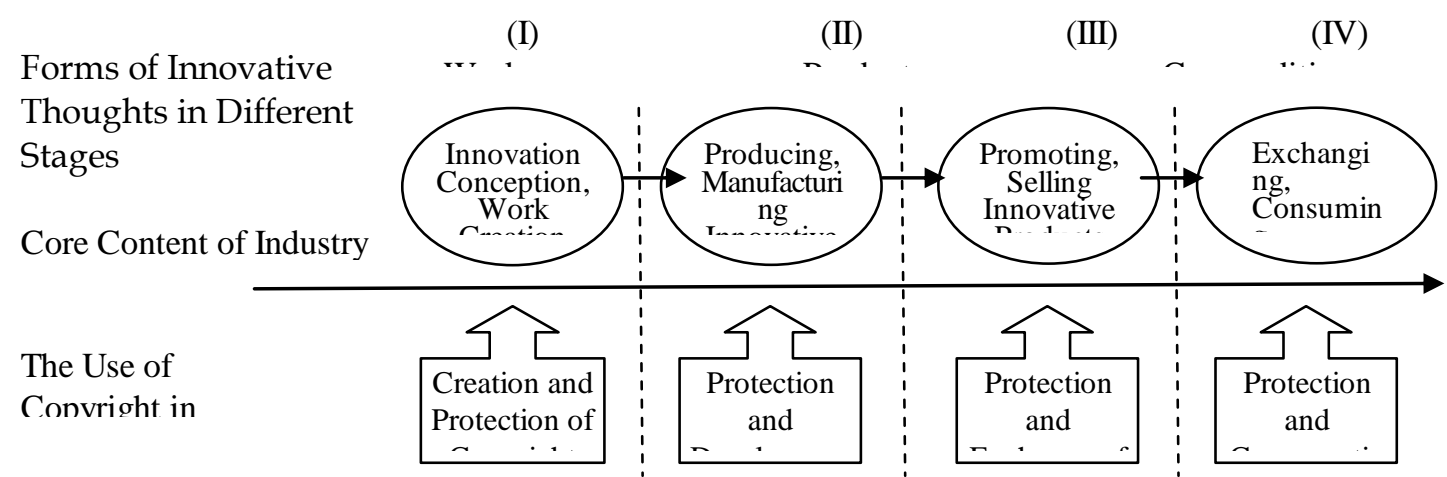

Figure 1: The Focus and Characteristics of Copyright Protection of the Different Stages in the Cultural Industry

The starting point of the value chain of the cultural industry is the intangible creative inspiration and conception of the creator. Followed by further creation, the initial concept transforms into displayable creative works that rely on corresponding carriers. After replication and production on a certain scale, the works are to become creative products or services, publicized and exchanged in the market. They ultimately become creative commodities (or consumer goods) for consumers to use or experience. As shown in Fig. 1.

As can be seen, in the process of adding value to the value chain, the core content of the activities of the cultural industry evolve around Stage I (Innovation Conception), Stage II (Replication and Production), Stage III (Promotion and Sales) and Stage IV (Use and Experience) respectively. The four stages manifest themselves correspondingly in the forms of innovative concept, work, product (or service) and commodity. However, from a copyright perspective, the formation of this value chain is at the same time the process from the creation of copyright to the development, exchange and consumption of copyright. Therefore, copyright protection should not only be throughout the entire value chain of the cultural industry, but also vary in intensity and focus according to the different characteristics of different stages.

\section{Empirical Analytical Studies}

We believe that the premise of pertinently presenting value-chain-based copyright protection method is analyzing and evaluating the specific effects due to copyright protection on the different stages of the value chain in the cultural industry. Because the number of works is an important carrier in the cultural industry, most countries determine the date of copyright based on the date of work completion, which in reality makes it impossible to know how many copyrighted works there are in a country or a region. However, there are verifiable statistics for copyright trade value, and more importantly, copyright trade value is an important indicator of the advancement of the cultural industry. Therefore this essay employs "copyright import and export trade value" to evaluate "the different stages of the value chain" and constructs the following quantitative analysis model to determine the impact of copyright protection on the stages of the value chain of the cultural industry.

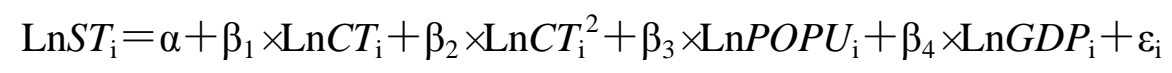

In this equation, $i$ values indicate different countries; $\mathrm{LnST}$, which is the natural log form of the level of copyright protection, is the response variable. $\mathrm{LnCT}$ is the natural log form of copyright import and export trade value per capita. Taking per capita data remediates the data distortion caused by employing the absolute value of a country's copyright import and export trade value, because the latter often neglects the size of the country. Theoretically, the relationship between LnCT and LnST is unclear. LnPOPU is the natural log form of each country's population. It reflects the influence of the social condition of a country on copyright trade value, and including it in the equation is to control the impact of copyright trade value on the strength of copyright protection. LnGDP is the natural log form of each country's gross domestic 
product, which reflects the economic capability of each country, and introducing it to the equation is also to control the impact of copyright trade value on the strength of copyright protection. $\varepsilon$ is the term for random error.

Our study sample is the data from fifty-one most representative countries around the world in the year 2008. Table 1 presents the statistical data.

Table 1. Raw Data of the Fifty-one Sample Countries in 2008

\begin{tabular}{|c|c|c|c|c|c|c|c|c|c|}
\hline Country/Region & $\begin{array}{c}\text { Level of } \\
\text { Copyright } \\
\text { Protection }\end{array}$ & $\begin{array}{c}\text { Copyright Import } \\
\text { and Export Trade } \\
\text { Value per capita (\$) }\end{array}$ & $\begin{array}{c}\text { Populatior } \\
(10,000)\end{array}$ & $\left.\mid \begin{array}{c}\text { GDP } \\
(\$ 100 \text { mil. })\end{array}\right)$ & Country/Region & $\begin{array}{c}\text { Level of } \\
\text { Copyright } \\
\text { Protection }\end{array}$ & $\begin{array}{c}\text { Copyright Import } \\
\text { and Export Trade } \\
\text { Value per capita } \\
(\$)\end{array}$ & $\begin{array}{c}\text { Population } \\
(10,000)\end{array}$ & $\begin{array}{c}\text { GDP } \\
\text { (\$100 mil.) }\end{array}$ \\
\hline Hungary & 6.33 & 1606 & 1004 & 1554 & Latvia & 5.083 & 501 & 227 & 337 \\
\hline Netherland & 6.05 & 2731 & 1645 & 8734 & Kenya & 2.492 & 11 & 3846 & 300 \\
\hline Chile & 5.94 & 141 & 1680 & 1707 & Brazil & 5.05 & 65 & 19154 & 16526 \\
\hline Austria & 5.905 & 5598 & 834 & 4147 & Canada & 5.047 & 1302 & 3331 & 14991 \\
\hline Luxemburg & 5.94 & 2404 & 49 & 581 & Spain & 5.025 & 777 & 4556 & 15939 \\
\hline Cyprus & 5.75 & 1306 & 108 & 254 & Estonia & 5.015 & 1804 & 134 & 235 \\
\hline Australia & 5.71 & 981 & 2150 & 10394 & Czech & 5.004 & 1117 & 1042 & 2161 \\
\hline France & 5.71 & 1290 & 6419 & 28318 & Poland & 4.98 & 343 & 3813 & 5294 \\
\hline Germany & 5.71 & 1533 & 8211 & 36345 & Ireland & 4.958 & 2055 & 443 & 2637 \\
\hline Italy & 5.71 & 1099 & 5983 & 22965 & Japan & 4.911 & 696 & 12770 & 48799 \\
\hline Norway & 5.71 & 1398 & 477 & 4462 & Malta & 4.896 & 1425 & 41 & 84 \\
\hline Sweden & 5.687 & 2558 & 922 & 4862 & Singapore & 4.782 & 9335 & 484 & 1894 \\
\hline Bulgaria & 5.652 & 165 & 762 & 518 & Lithuania & 4.653 & 572 & 336 & 473 \\
\hline US & 5.6 & 991 & 30438 & 142969 & New Zealand & 4.622 & 723 & 427 & 1178 \\
\hline Argentina & 5.598 & 80 & 3971 & 3267 & Albania & 4.489 & 66 & 318 & 130 \\
\hline Croatia & 5.53 & 494 & 443 & 699 & Korea & 4.246 & 1109 & 4861 & 9314 \\
\hline Portugal & 5.512 & 648 & 1062 & 2519 & India & 4.193 & 39 & 113996 & 12138 \\
\hline Iceland & 5.51 & 1386 & 32 & 169 & Malaysia & 4.18 & 988 & 2750 & 2218 \\
\hline Romania & 5.447 & 219 & 2151 & 2001 & Thailand & 4.153 & 282 & 6827 & 2726 \\
\hline Israel & 5.4 & 4294 & 731 & 2021 & China & 3.988 & 173 & 132466 & 45218 \\
\hline Slovenia & 5.381 & 1071 & 202 & 546 & Belarus & 3.955 & 117 & 960 & 608 \\
\hline Slovak & 5.316 & 860 & 541 & 985 & Georgia & 3.888 & 43 & 438 & 128 \\
\hline Belgium & 5.239 & 5965 & 1071 & 5054 & Philippines & 3.646 & 47 & 9017 & 1736 \\
\hline UK & 5.202 & 2650 & 6139 & 26575 & Indonesia & 3.57 & 35 & 23495 & 5102 \\
\hline Greece & 5.139 & 557 & 1124 & 3470 & Morocco & 2.915 & 47 & 3132 & 889 \\
\hline Finland & 5.128 & 3451 & 531 & 2705 & & & & & \\
\hline
\end{tabular}

(Author's note: the level of copyright protection comes from our compilation[8]and calculation; copyright import and export trade value per capita comes from UNCTAD GlobStat Database and compiled by author; population and GDP comes form World Bank.)

\section{Policy Advice}

By means of theoretical analysis and empirical studies, we believe that in the loop of the cultural industry, copyright protection and the level of copyright trade has an inverted $U$ relationship. This empirical result corresponds to the four hypotheses of this essay, based on which we now have a good understanding of the different copyright protection methods for the different stages of the value chain of the cultural industry. (Table 2) 


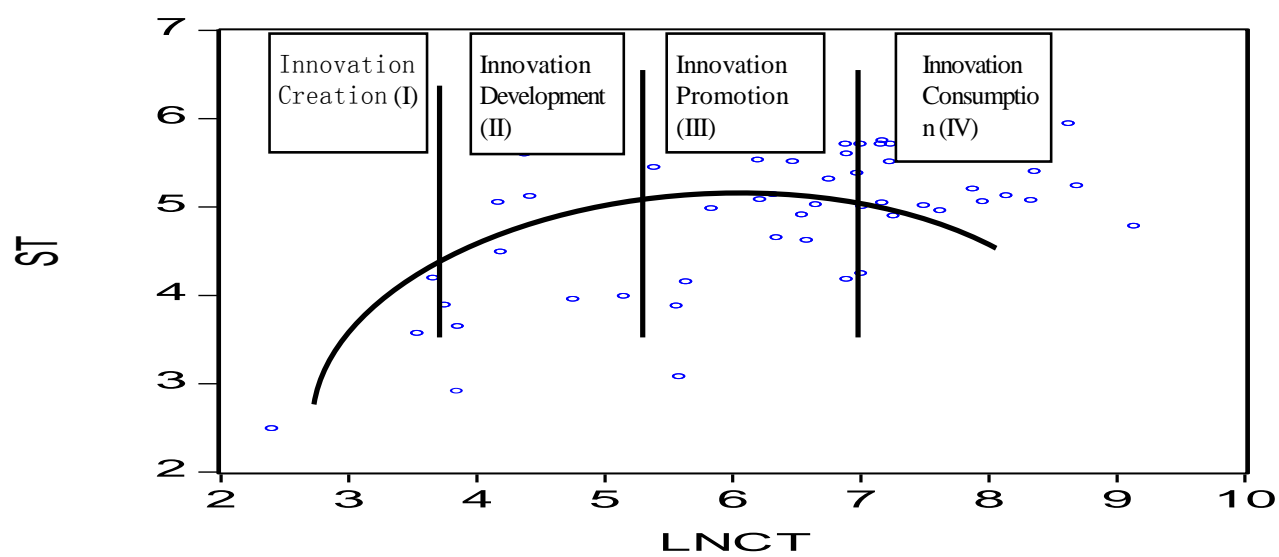

Table 2: Copyright Protection from a Value Chain Perspective

Specifically, during the creation stage (I), because of the small quantity of works in the cultural industry market, the level of copyright trade is low. During the consumption stage (IV), the promotion and sales of innovative products on a large scale has completed, and the level of copyright trade is in decline while also breeds the birth of a new cycle. Therefore, during these two stages we should adopt loose copyright protection methods. In order to do so, three paths can be taken. First is to the concept of limited interests. In Germany, limited interest is a concept of copyright law. It explains the crucial importance of reasonable and necessary limitations on the rights owners to maintain and promote social and public life. Second is to determine the principle of proper use. In the United States, legislators put limitations on copyright for public good, allowing the reproduction of documents for personal or academic use, the reverse engineering of software under restrictions, and the quotation of news articles and books. Third is to shorten the term of copyright protection. The purpose of copyright protection is to give enough incentive to copyright holders, thus the term of copyright protection need only to cover the period during which the copyright holder may profit beyond his or her investment.

During the development stage (II), the design and creation period has completed, some of the copyrighted works start to appear on the cultural market. And during the promotion stage (III), copyrighted works has started to circulate in the market on a large scale. Therefore during these two stages, we should further strengthen the level of copyright protection and adopt stricter standards. To this end, the following measures can be taken. First, perfect the copyright legislature system. Since the establishment of copyright law in Japan, it has been amended thirty five times. Korea and Taiwan have amended the copyright law seventeen times; Singapore seven times; Malaysia six times; India five times, yet we have only done so twice. Japan, with the most amendments, is one of the countries with the most mature copyright protection in Asia. The frequency of amending copyright law is proportionate to the maturity of the legislature of copyright protection. Therefore, our country must refine copyright protection system and perfect related management system. Second, strengthen law enforcement capacity. Copyright management sections should think in long terms, consistently fighting against piracy. It is especially undesirable to tighten control when under heat and loosen control when not. Rather, we should maintain the consistency in copyright law enforcement. Third, promote the cultivation of copyright culture. In 2009, State Intellectual Property Office launched a nation-wide "Chinese Public Intellectual Property Literacy Survey" to ensure the smooth implementation of "National Intellectual Property Strategy". The result shows that only $0.8 \%$ of the public can correctly identify patent rights, copyrights, trademark rights, trade secrets, plant variety rights, integrated circuit layout design rights, geographical indications, unfair competition, scientific discovery rights and appearance design. Among all identified intellectual property content, patent is the most known, with $85.9 \%$ of the public answered correctly. Copyright comes next, with $75.7 \%$. Only $35.2 \%$ of netizens has correct recognition about sharing copyrighted works on the Internet. This in a way reflects the lack of basic copyright knowledge and the low copyright literacy among Chinese citizens, urging the society to cultivate a social atmosphere that respects knowledge, advocates innovation and abides the law. 


\section{Conclusion}

Because of the double-edged nature of the copyright system, its implementation has always been a difficult choice. On the one hand, it promotes and encourages the supply of innovative works, which gives copyright owners or creators more opportunities to renew, publicize and develop current works and produce more positive social benefits. On the other hand, copyright is monopoly in nature. In the pursuit of profit maximization, it is highly likely for copyright owners to expand monopoly profit at the expense of social and public benefit, which impedes the growth of knowledge in the entire society and hinders public access to copyrighted works, resulting in negative social benefits. Therefore, when drafting and publishing copyright laws and policies, it is difficult to enforce a single level of copyright protection. Rather, we must propose targeted copyright protection methods and paths based on the different characteristics of the different stages of the value chain of the cultural industry to promote the development of the cultural industry, maximizing the social benefit of copyright protection, overcoming the limitations of the copyright system and minimize or eliminate the negative impact of the copyright institution. In addition, based on different copyright protection in different stages of the value chain of the cultural industry and by analyzing value activities and characteristics of different stages, further research should focus on providing detailed methods and strategies to promote the development of copyright protection in the cultural industry.

\section{Acknowledgement}

This research was financially supported by the National Social Science Fund ——Youth Projects (11CGL108).

\section{References}

[1] Fu Jiayi, The Theory of Technological Innovation (Beijing: Tsinghua University Press, 2006).

[2] Zhao Yulin, The Economics of Innovation (Beijing: China Economic Publishing House, 2006).

[3] Wang Dan, "On the Legal Protection of Market-based Operations in the Cultural and Creative Industries", Journal of Jilin Provincial Institute of Education 12 (2009): 31-32.

[4] Li Wanhong and Bi Kexin, "Relationship between the Innovation Capabilities and the Copyright Protection in Chinese Software Industry," Forum on Science and Technology in China 6 (2010): 67-72.

[5] Yao Jiejing and Peng Hui, "Analysis of Grey Correlation between Copyright Protection and Innovation Capability of Cultural Industry," Journal of Capital University of Economics and Business 2 (2011): 31-37.

[6] Cao Xinming, "The Research on the Rights-weakening and Interests-sharing Theory," Journal of the Postgraduate of Zhongnan University of Economics and Law 1 (2007): 6-14.

[7] Yao Jiejing and Peng Hui, "Empirical Studies on the Relationship Between Copyright Protection and Copyright Trade," Science-Technology and Law 1 (2011), 92-97.

[8] Peng Hui and Yao Jiejing, "The Construction of the Copyright Protection Index System and Strength Calculation," Document, Information and Knowledge 5 (2010): 72-83. 